International Journal of Linguistics Studies (IJLS)

ISSN: 2754-2599

DOI: $10.32996 / \mathrm{ijls}$

Journal Homepage: www.al-kindipublisher.com/index.php/ijlss

\title{
The Distribution Patterns of Valency-changing Verbs: An Approach of Quantitative Linguistics
}

\author{
Da Qi ${ }^{1}$ and Hua Wang ${ }^{2} \square$ \\ ${ }^{1}$ School of International Studies, Zhejiang University, Hangzhou, China \\ ${ }^{2}$ School of Foreign Languages, Dalian University of Technology, Dalian, China
}

$\square$ Corresponding Author: Hua Wang, E-mail: wanghuazju@163.com

\section{ARTICLE INFORMATION}

Received: 25 September 2021

Accepted: 11 October 2021

Published: 1 November 2021

DOI: $10.32996 / \mathrm{j} / \mathrm{l}$.2021.1.2.7

\section{KEYWORDS}

Valency Theory, Valency-changing phenomena, Distribution Patterns, English Verbs

\section{ABSTRACT}

The present study attempts to explore the distribution patterns of the valencychanging verbs from the perspective of quantitative linguistics. We took authentic spoken language data as the research materials. The corpus used in this paper is a selfbuilt spoken English corpus containing about 21,000 words. We half-manually annotated the corpus with the help of SpaCy, a natural language processing tool. According to the annotation results and statistical data, we obtained a total of 217 valency-changing English verbs and 248 sentence components governed by them. After analysis, the current study came to the following conclusions: First, bivalent verbs are most frequent among the three types of valency-changing verbs; second, after fitting all the language data to different probability distributions, we found that the rank-frequency distributions of all the valency-changing English verbs with different numbers of obligatory arguments obey the power law, and the frequencies of bivalent valency-changing verbs obey other kinds of distributions such as the mixed Poisson distribution.

\section{Introduction}

It is generally accepted that the valency theory was born in France and developed in Germany, and it is a major area of interest within the field of dependency grammar since its birth in Tesnière (1959).

By definition, valency is a kind of ability that a word has to form specific patterns with other constituents in the sentence (Herbst, 1988). Specifically, valency indicates the complement pattern of a word, be it a verb, a noun, or an adjective, and its complements are usually obligatory and optional arguments. The existing studies to date focus more on the valencies of verbs, which open up slots around them and attract arguments to fit in.

Verbs can be divided into four categories: those with no actant, one actant, two actants, and three actants, which are governed by the verb in question. Tesnière (1959) uses two similes to further illustrate this concept. The first one is the comparison between a verb and an atom with a hook, which attracts a certain number of actants to serve as its dependents, and the number of hooks is exactly the verb's valency. He then likens a verbal node to a theatrical performance, in which the verbs, the actants, and the circumstants respectively become the process, the actors, and the circumstances. These two similes reflect his two basic views towards the essence of valency, which has both semantic and syntactic features.

Semantic valency denotes the semantic roles of the arguments, e.g., agents/patients, and their semantic class, e.g., \pm human, \pm male (Liu, 2009). It is associated with the inherent meaning of the verb in question. Syntactic valency concerns the number and syntactic forms of the arguments, ensuring their proper syntactic positions.

Copyright: (C) 2021 the Author(s). This article is an open access article distributed under the terms and conditions of the Creative Commons Attribution (CC-BY) 4.0 license (https://creativecommons.org/licenses/by/4.0/). Published by Al-Kindi Centre for Research and Development, London, United Kingdom. 
In order to achieve that goal, quantitative linguistics (QL) can be of great help. QL is a linguistic branch that "studies the multitude of quantitative properties which are essential for the description and understanding of the development and the functioning of linguistic systems and their components" (Köhler, 2012:9). It emphasizes the methods of building up models and focuses on the quantitative properties as well as the synergetic relations between them (Liu, 2017). In this sense, QL, like any other empirical subject, stresses quantitative approaches such as (mathematical) statistics, probability, etc., which can "provide us with a conceptual and methodological means to enter deeper layers of the complex structure of reality and to better understand the object of our interest" (Köhler, 2012: 15).

Thus, we can analyze and describe the English verb valency by means of the models and laws in QL, e.g., the rank-frequency distributions of linguistic entities. Moreover, together with the investigations on its relevant linguistic phenomena, the current study may pave the way for some sound theories about valency in the future.

As stated earlier in this section, there are four genres of verbs according to the number of their obligatory semantic-syntactic valencies. Do the valency-changing verbs with different numbers of obligatory semantic-syntactic arguments display similar patterns?

\section{Literature Review}

\subsection{Theoretical Studies on the Valency Theory}

Valency derives from the Latin word valentia and is put forward in linguistics by analogy with the chemical valency. Lucien Tesnière, the founder of the valency theory, gave the definition of valency in his masterwork Éléments de syntaxe structurale and developed a set of grammar theories on the basis of it. Tesnière's definition of valency is considered as the core issue of modern valency theory. Since then, valency theory has been widely applied to the grammatical approach.

With so many scholars engaging in this field, the definition of valency varies, and some typical ones are as follows. Helbig and Schenkel (1978) argued that valency indicates the abstract relationship between a verb and other elements governed by it. They held the view that syntactic valency refers to the ability of a verb to open up a certain number of slots around it and to seek other elements to fill in. Engel (1982) deemed valency as an ability of the predominance of words. It is common sense that verbs possess the capacity to dominate adverbs, which are therefore not considered as valency. However, some verbs can govern one argument, and others can rule two or even three arguments. This kind of ability can be regarded as valency. Heringer's (1993a) view on valency was that the feature of a verb is on the acceptance or requirement of a particular type of complement. Heringer (1993b) also put forward that valency is comprised of three types: quantitative valency, qualitative valency, and selectional valency. Allerton (1982) regarded valency as a kind of ability of a verb or noun that combines with other constituents in the sentence. Fischer (1997) considered valency as the ability of a language unit that forms larger ones with certain sentence elements. In his opinion, valency is a general concept that concerns every sort of language unit.

Valency grammar is a system of syntax that is also called continental grammar, the critical point of which is that verbs predetermine the sentence structure (Teubert, 2007). Matthews (2007) defined the scope of valency in grammar. "Valency, to sum up, is in principle independent of dependency, headship or governorship; it is a property of lexical units in relation to constructions; and it is specifically of units assigned to subcategories" (Matthews, 2007:11). The first English valency dictionary, A Valency Dictionary of English (VDE) written by Thomas Herbst (2004), stated that valency is an important area of the description of English, and argued that it plays a major part in foreign language teaching. "Valency, however, is also a common source of errors in foreign language learning and thus a very important factor in teaching English as a foreign language" (Herbst et al., 2004:vii).

At the end of the 1970s, the valency theory was introduced into China and became a hot issue in the 1980s. Many Chinese linguists have given an explanation about what valency is. Cheng defined valency from the perspective of syntax: "Valency is a kind of significant tool that deals with syntactic structure. Since the middle of the last century, various methods of research relating to the syntactic structure are within the framework of structuralism as well as valency" (Cheng, 2005:109). Hua (2004) regarded valency as the ability of verbs to open up a number of spaces that can be filled by complements to strike a balance of sentences. In other words, it refers to the quantities of certain complements dominated by a verb. Therefore, Hua's view on valency is similar to that of Helbig's. In Zhou's (1994) view, valency means that a word based on its semantics requires certain kinds of elements to combine with it in the process of sentence construction.

In a nutshell, there are slight differences in each of these definitions, but they all share something in common: valency is a capacity of words, and it opens up around the words some spaces, which determine what kinds of words can fill them in (Liu, 2006; Liu, 2009). However, there exist few studies concerning how valency changes in certain conditions, to which the current study hopes to make some contributions.

\subsection{Empirical Studies on the Valency Theory}


The valency grammar is employed to describe the valency structure of words, the study on which greatly contributes to the development of the valency theory. Herbst (2007) proposed that the valency approach is one of the most systemic attempts to represent complementation structures of verbs, adjectives, and nouns. He demonstrated that "valency is definitely one of the more messy aspects of language" (Herbst, 2007:27). Therefore, according to the bank of English, he explains valency patterns of frequently used verbs, adjectives, and nouns; and his research product VDE becomes the first English valency dictionary that nurses the valency studies of the English language. Roe (2007) compared language problems encountered by German and English learners based on small errors from the perspective of valency. Fischer (2007) investigated German verbs by comparing them with English ones and discovered that English is more ambiguous than German both semantically and syntactically. Ickler (2007) carried out a study showing that "sentence patterns can be related to specific functional meanings which, to a certain extent, can be described independently of the verbal lexeme" (Ickler, 2007:253). Reichardt (2013) investigated the interconnection of local grammar, meaning, and translation equivalence by taking consider as a case. Based on corpus analysis, his research indicates that "from the perspective of translation, language is less rule-based and less phraseological than is assumed" (Reichardt, 2013:iii). Haugen presented a corpus-based investigation of 180 polyvalent adjectives patterns to shed light on "whether valency is word-based or construction-based" (Haugen, 2013:35). In this study, he examined whether predicators take complements, and data show that predicators indeed take complements in the sense that they are idiosyncratically connected to a range of valency patterns.

Corpus-based and corpus-driven studies of verb valency patterns have also garnered many researchers' attention in recent years (Zhen \& Yang, 2015, 2016; Zhen, 2017; Liu \& Du, 2017). For example, Zhen and Yang (2015) described the verb valency in the Chinese Learner English Corpus (CLEC) by taking the verb to consider as the study object. Their study explored a system of valency patterns and employed it in the analysis of Chinese English learners, revealing that Chinese English learners differ from native speakers both in the valency types and numbers. Zhen (2017) examined how to describe lexical meanings and their grammatical structure together from the perspective of valency patterns. Their results showed that different valency patterns could represent different meanings, as well as the meaning-structure complex organized by lexical meaning and grammatical structure.

It is clear to see from the above that the current empirical studies have covered many aspects of the valency theory and made many achievements in the semantic and syntactic levels. However, just like the blank in the theoretical studies, there is still a large gap in the patterns of valency-changing phenomena, which might hinder the development of the valency theory.

\section{Methods and Materials}

In order to observe and describe valency from the dynamic perspective (the valency-changing phenomena), we need to study the authentic data in real contexts, especially the data in spoken language, which reflects the most dynamic perspective of a language (Jespersen, 1992). When approaching the valency-changing phenomena in spoken English, we can hardly find studies on the increase of verbs' arguments, while the omission of certain participants (the reduction of valency) is widely applied (Nariyama, 2004). Hence, we will treat the omission of arguments as the change of valency in this study.

According to Quirk et al. (1985), there are five criteria to define ellipsis in the strictest sense: first, the missing words can be exactly recovered with no ambiguity; second, the elliptical construction is lack of some obligatory grammatical elements; third, the missing words make the sentence complete after being inserted (without altering the original meaning); fourth, the ellipted words are textually recoverable; fifth, the form of the missing words shall be the same with their precedents. However, when determining the actual valency of a verb, we cannot use all of the five criteria, because the valency of a verb is usually determined from the semantic perspective, which only requires the identification of participants $(\mathrm{Wu}, 1993)$. For instance, when dealing with the constructs as I do, we can easily notice that it violates the first criterion of ellipsis (there are many possibilities for the omitted patient(s)), but it is rather effortless to figure out what the omitted participant(s) is/are when taking the context into account. In this case, the determination of valency perfectly corresponds with the "situational ellipsis" mentioned in Quirk et al. (1985), which is commonly used in the interpretation that depends on the knowledge of a precise extralinguistic context.

Based on the number of obligatory valencies, verbs can be grouped into four categories, i.e., zero-valent verbs, univalent verbs, bivalent verbs, and trivalent verbs. The actual valencies of verbs can be marked up manually. After the annotation process, we can find out the regular patterns of the change of valencies with the help of quantitative methods. To accomplish the tasks above, we built a small corpus of modern spoken English, in which the ellipted valencies are marked manually.

As stated earlier, spoken English is a good resource for researchers to study the elliptical phenomena, hence the changing of English verb valency. However, the natural spoken languages in people's daily life are hard to record, and thus TV programs are applied as the research materials in this study. We sorted out 9 pieces of CNBC interviews and transcribed them. The dialogues between hosts/hostesses and guests were gathered to form a spoken English corpus, which contains about 21,000 words (tokens), and these interviews are all dated somewhere between August 2019 to January 2020. Some detailed information about this corpus is shown in Table 1 below. 
Table 1: The Basic Information about the Corpus

\begin{tabular}{llll}
\hline No. & Names of Guests & Dates of Interviews & Word Counts \\
\hline 1 & Dave Calhoun & January 29, 2020 & 2,717 \\
2 & Gwyneth Paltrow & January 6, 2020 & 1,698 \\
3 & James Gorman & January 22, 2020 & 2,018 \\
4 & John Williams & December 18, 2019 & 1,878 \\
5 & Kewsong Lee & December 11, 2019 & 1,968 \\
6 & Michael Wirth & January 7, 2020 & 1,577 \\
7 & Mitch McConnell & September 30, 2019 & 2,374 \\
8 & Peter Navarro & December 31, 2019 & 3,061 \\
9 & Ray Dalio & August 23 2019 & 3,802 \\
Total & & & 21,093 \\
\hline
\end{tabular}

After gathering the raw data, we completed the task of word segmentation in SpaCy, an automatic natural language processing package in Python. Based on the criteria of ellipsis mentioned earlier, we then manually marked up the changed valencies in Microsoft Excel. According to the number of obligatory valencies, verbs can be divided into four categories: zero-valent verbs, univalent verbs, bivalent verbs, and trivalent verbs. Zero-valent verbs take no complements and do not occur in English, but they can be found in languages like Chinese, in which the weather verbs like rain(s) have no argument. Univalent verbs govern only one dependent, which is usually the subject in that sentence, and those verbs are also called intransitive verbs, e.g., run in I run. Bivalent verbs have two obligatory actants, with one being the subject and the other object. They are also known as transitive verbs in English, e.g., love in I love you. Trivalent verbs are those that take three obligatory arguments, which are respectively the subject, the direct object, and the indirect object. These kinds of verbs are the dative verbs in contemporary English, e.g., give in I give him a book.

After marking up the changed valencies, we accomplished the annotation of other necessary information, as shown in Table 2. The valency-changing verbs ellipted in the original sentence were marked with the letter "E". Moreover, some verbs might be continuous throughout the discourse, and thus their indexes were also marked up accordingly in the "No." column. The annotation process was accomplished in Microsoft Excel, and a selection is shown in Table 2 below.

Table 2 shows the verbs and their different valencies. The third and fourth columns respectively display the syntactic-semantic valencies and the actual valencies of the verbs.

Table 2: The Annotation of the Valencies of Verbs

\begin{tabular}{llll}
\hline Verbs & & $\begin{array}{l}\text { Syntactic-semantic } \\
\text { valency }\end{array}$ & Actual valency \\
\hline Text & No. & 2 & 1 \\
\hline let & 96 & 2 & 0 \\
make-E & 181 & 2 & 1 \\
know & 239 & 1 & 0 \\
look & 290 & 1 & 0 \\
sandbagging-E & 344 & 2 & 1 \\
provide-E & 408 & 2 & 1 \\
provide-E & 411 & & \\
\hline
\end{tabular}

As discussed in the Introduction, the syntactic-semantic valency is the static and maximum state of a verb valency. We looked it up in the Erlangen Valency Patternbank (EVP), a VDE-based online valency pattern bank that is currently available at http://www.patternbank.uni-erlangen.de. A selection of the information provided by the EVP is displayed in Table 3, which demonstrates the valency pattern of one of the verb buy's senses.

As shown in Table 3, this valency dictionary of English provides the following information: the verb's valency number (the first column), its valency patterns in the active voice (the second column), and its valency patterns in the passive voice (the third column). The examples of the verbs in actual use can be found in the VDE, based on which we determined the semantic-syntactic valencies of the verbs in our corpus. However, as stated in the preceding section, VDE only contains static information about the verbs. The dynamic description of a verb valency is given by the actual valency, which is annotated in the fourth column in Table 2 . 
Table 3: The Valency Pattern of One of the Verb buys Senses

\begin{tabular}{|c|c|c|}
\hline Number of valencies & Active & Passive \\
\hline 1 & $\mathrm{SCU}+\mathrm{VHCact}$ & \\
\hline \multirow[t]{3}{*}{2} & $\mathrm{SCU}+\mathrm{VHCact}+\mathrm{NP}$ & NP + VHCpass | (+ by_phrase) \\
\hline & $\mathrm{SCU}+$ VHCact + at_NP & $\mathrm{NP}+\mathrm{VHCpass}+$ at $\mid$ (+ by_phrase) \\
\hline & $\mathrm{SCU}+\mathrm{VHCact}+$ by_NP & \\
\hline \multirow[t]{8}{*}{3} & $\mathrm{SCU}+\mathrm{VHCact}+\mathrm{NP} 1+\mathrm{NP} 2$ & $\begin{array}{l}\text { NP1 + VHCpass + NP2 | (+ by_phrase) } \\
\text { NP2 + VHCpass + NP1 | (+ by_phrase) }\end{array}$ \\
\hline & $\mathrm{SCU}+\mathrm{VHCact}+\mathrm{NP}+\operatorname{AdjP}$ & NP + VHCpass + AdjP | (+ by_phrase) \\
\hline & $\mathrm{SCU}+\mathrm{VHCact}+\mathrm{NP}+$ at_NP & NP + VHCpass + at_NP | (+ by_phrase) \\
\hline & $\mathrm{SCU}+\mathrm{VHCact}+\mathrm{NP}+$ by_NP & $\mathrm{NP}+\mathrm{VHCpass}+$ by_NP | (+ by_phrase) \\
\hline & $\mathrm{SCU}+\mathrm{VHCact}+\mathrm{NP}+$ for_NP & $\mathrm{NP}+\mathrm{VHCpass}+$ for_NP | (+ by_phrase) \\
\hline & $\mathrm{SCU}+\mathrm{VHCact}+\mathrm{NP}+$ from_NP & $\mathrm{NP}+\mathrm{VHCpass}+$ from_NP| (+ by_phrase) \\
\hline & $\mathrm{SCU}+\mathrm{VHCact}+\mathrm{NP}+$ off_NP & NP + VHCpass + off_NP | (+ by_phrase) \\
\hline & $\mathrm{SCU}+\mathrm{VHCact}+\mathrm{NP}+$ with_NP & NP + VHCpass + with_NP I (+ by_phrase) \\
\hline
\end{tabular}

After completing all the annotation procedures, we employed Microsoft Excel and the Altmann Fitter to complete the fitting tasks. The Altmann Fitter is an interactive program, which is mainly applied in the iterative fitting of univariate discrete probability distributions to frequency data (Altmann-Fitter, 2013). It contains over 200 individual probability distributions that can be used in various ways. With the help of these two programs, we analyzed whether the rank-frequency distributions of the verbs in our corpus obey the power law and whether their frequencies fit other distributions. After that, we carried out the same procedures to the frequencies of the verbs with different valencies.

\section{Results and Discussion}

The present study deals with the distribution patterns of the valency-changing English verbs. As shown in Table 2, English verbs are often involved in such phenomena as valency reduction rather than valency increase. Thus we focus on the verbs whose valencies are omitted. According to the statistics of our English spoken corpus, we altogether get 217 valency-changing verbs. Table 4 shows the number and proportion of each category of the verbs.

Table 4: The Frequencies and Proportions of Different Genres of Verbs

\begin{tabular}{lll}
\hline Genres of Verbs & Frequency & Proportion \\
\hline Univalent verbs & 23 & $10.60 \%$ \\
Bivalent verbs & 191 & $88.02 \%$ \\
Trivalent verbs & 3 & $1.38 \%$ \\
Total & 217 & $100.00 \%$ \\
\hline
\end{tabular}

As discussed in the Methods and Materials, there is no zero-valent verb in English. Thus we only analyze the univalent, bivalent and trivalent verbs in the current study. Table 4 displays that the frequency of univalent verbs is 23 , the frequency of bivalent verbs 191 , and that of trivalent verbs is 3 . Thus, bivalent verbs, which account for $88.02 \%$ of the whole verbs, are the most frequent ones in our corpus. Based on previous studies (Köhler \& Altmann, 2009; Jin \& Liu, 2018), the rank-frequency distributions of valencies are hypothesized to obey some common rank-frequency distributions. Therefore, the current study hypothesizes that the rankfrequency distributions of the valency-changing verbs may abide by the power law, which can be demonstrated by the following formula:

$$
y=a x^{-b}
$$

We then went on to explore the rank-frequency distributions of the valency-changing verbs as a whole, and the frequency of each verb is listed in Table 5.

Table 5: The Frequency of Each English Verb in Our Corpus 


\begin{tabular}{llllll}
\hline Verbs (by token) & Rank & Frequency & Verbs (by token) & Rank & Frequency \\
\hline is & 1 & 32 & be & 9 & 4 \\
look & 2 & 18 & buying & 10 & 4 \\
let & 3 & 17 & found & 11 & 4 \\
thank & 4 & 10 & see & 12 & 4 \\
am & 5 & 9 & $\ldots$ & $13 \sim 18$ & 3 \\
have & 6 & 7 & $\ldots$ & $19 \sim 27$ & 2 \\
are & 7 & 7 & $\ldots$ & $28 \sim 86$ & 1 \\
listen & 8 & 6 & & & \\
\hline
\end{tabular}

Based on the statistical results shown in Table 5, we applied the calculation tools in Excel to carry out the fitting analysis, observing whether their rank-frequency distribution obeys the power law. The fitting results are shown in Figure 1.

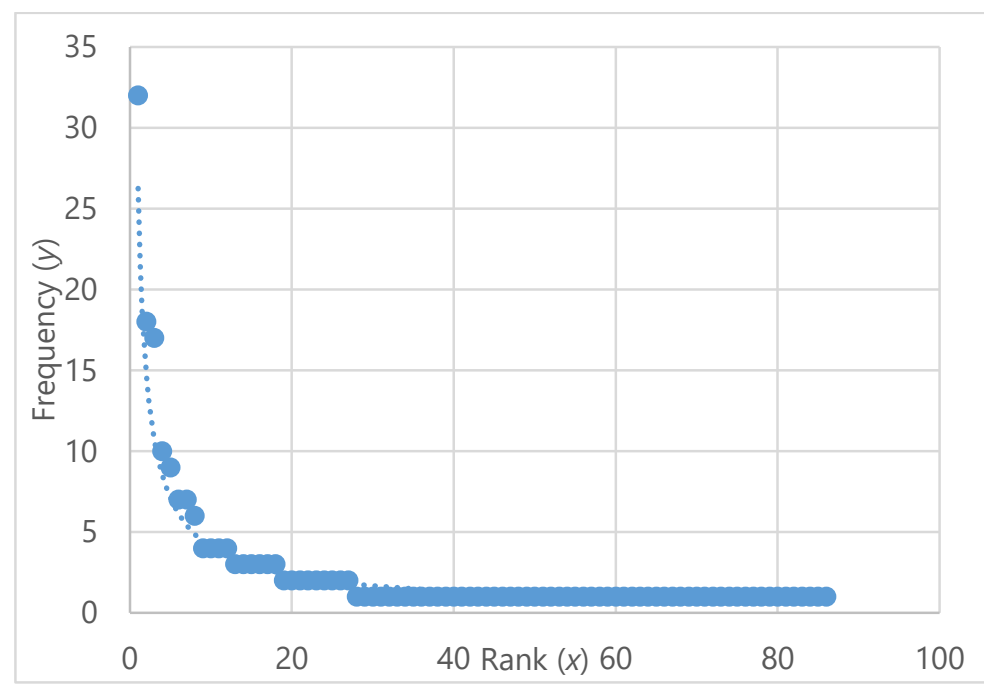

Figure 1: The Rank-frequency Distribution of All the Verbs in Our Corpus

As displayed in Figure 1, the rank-frequency distribution of the valency-changing verbs obeys the power law, with its coefficient of determination $R^{2}$ being 0.91 . The values of parameters $a$ and $b$ are respectively 26.229 and 0.81 .

Then we respectively explored whether the frequencies of different genres of verbs obey the power law. Here we only dealt with those of the univalent and bivalent verbs since the number of the trivalent verbs is too small to get reliable statistical results. The frequencies of the verbs with different semantic-syntactic valencies are listed below in Table 6 .

Based on the statistics above, we made the fitting tests to explore whether the rank-frequency distributions of different verbs obey the power law, and the results are shown in Figure 2(a) and Figure 2(b).

According to Figure 2(a) and Figure 2(b), we can arrive at the conclusion that the rank-frequency distributions of the univalent and bivalent verbs in our corpus abide by the power law. The parameters $a$ and $b$ in Figure 2(a) and Figure 2(b) are respectively 11.07 and 1.401 , and 23.45 and 0.8 . The coefficients of determination $R^{2}$ are 0.9157 and 0.9218 , respectively.

Table 6: The Frequencies of the Verbs with Different Semantic-syntactic Valencies

\section{Univalent verbs}

Verbs

token
Bivalent verbs

Frequency Verbs by Rank token
Trivalent verbs

Frequency Verbs by Rank token
Frequency 


\begin{tabular}{|c|c|c|c|c|c|c|c|c|}
\hline look & 1 & 11 & is & 1 & 32 & ask & 1 & 1 \\
\hline listen & 2 & 6 & let & 2 & 17 & call & 2 & 1 \\
\hline go & 3 & 2 & am & 3 & 8 & give & 3 & 1 \\
\hline happened & 4 & 1 & thank & 4 & 8 & & & \\
\hline relax & 5 & 1 & are & 5 & 7 & & & \\
\hline sandbaggin & 6 & 1 & look & 6 & 7 & & & \\
\hline \multirow[t]{5}{*}{$\begin{array}{l}\text { g } \\
\text { shut }\end{array}$} & 7 & 1 & buying & 7 & 5 & & & \\
\hline & & & $\ldots$ & $8-12$ & 4 & & & \\
\hline & & & $\ldots$ & $13-17$ & 3 & & & \\
\hline & & & $\ldots$ & $18-26$ & 2 & & & \\
\hline & & & $\ldots$ & $27-76$ & 1 & & & \\
\hline
\end{tabular}

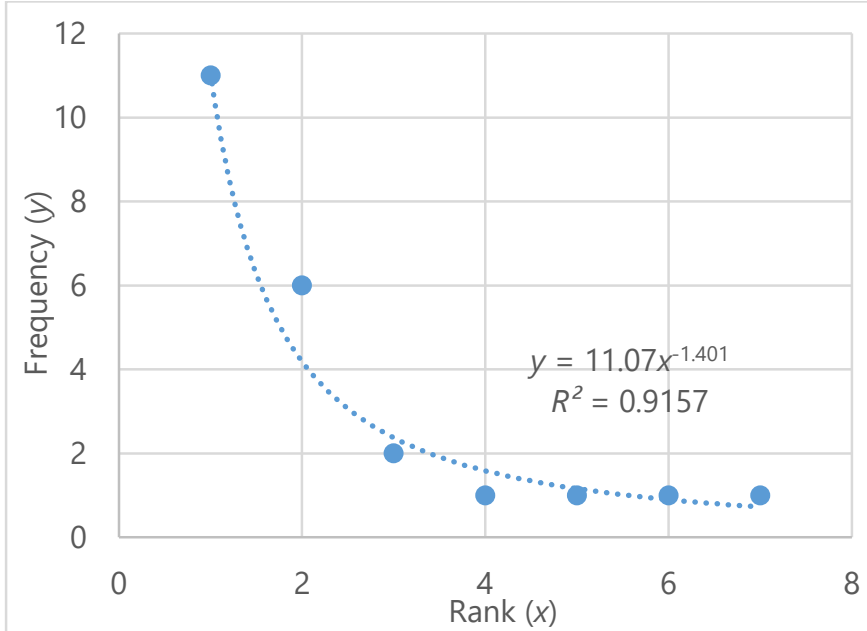

(a)

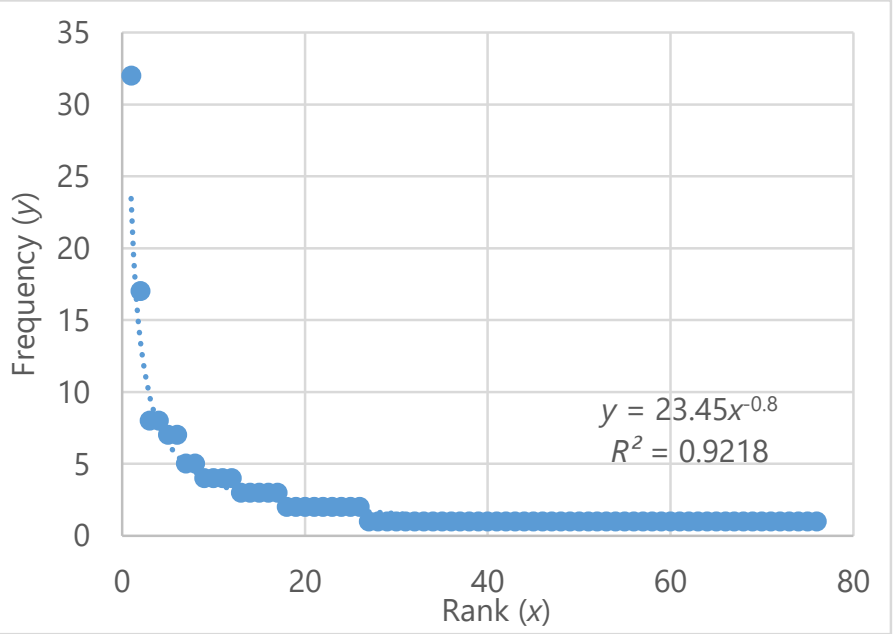

(b)

Figure 2: The Rank-frequency Distribution of Univalent Verbs (a) and Bivalent Verbs (b)

In addition, we also aim to explore whether the rank and frequency of valency-changing verbs fit other sorts of distributions, and thus we imported the data to the Altmann Fitter, which can automatically calculate more than 200 kinds of distributions in short order, to complete all the fitting work. We only found out that the frequencies of bivalent verbs obey the mixed Poisson distribution with the probability of the found $X^{2}$ value $P\left(X^{2}\right)$ being 0.4163 and the coefficient of determination $R^{2} 0.9781$. The result is displayed in Figure 3.

These fitting results perfectly answered our research question, i.e., the rank-frequency distribution of the valency-changing verbs obeys the power law, and those of the univalent verbs and bivalent verbs also abide by it. Similar to the fitting results of previous studies on the rank-frequency distribution of verb valencies, the work we have done might indicate that the power law is prevalent in the field of verb valency studies. Moreover, the finding that the frequencies of bivalent verbs fit the mixed Poisson distribution might open the door for a more general theory of the distribution patterns of verb valencies. Further studies are needed to figure that out. 


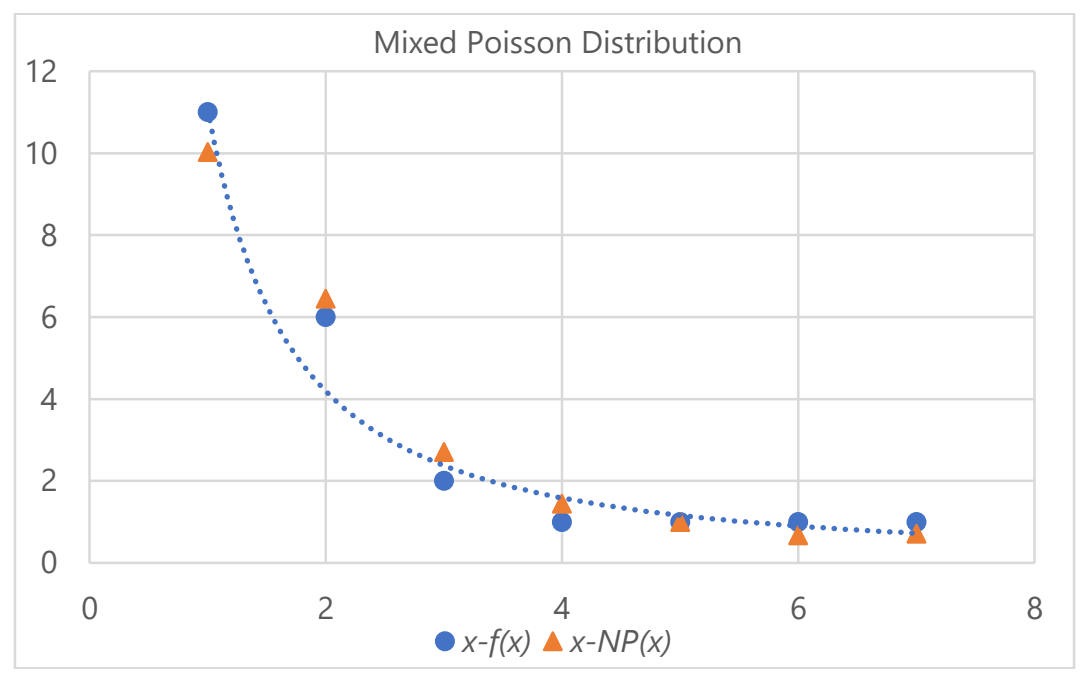

Figure 3: The Mixed Poisson Distribution of Bivalent Verbs

Note: 1) NP means the multiplication of the sample size $(N)$ and the probability $(P)$ of each sample;

2) $f(x)$ is the actual observed value, while $N P(x)$ is the theoretical value.

\section{Conclusion}

The present study mainly aims to describe the valency-changing phenomena of English verbs by examining the distribution patterns of the valency-changing verbs from the perspective of quantitative linguistics.

We found that the bivalent verbs (the verbs with two obligatory arguments) are the most frequent in the valency-changing phenomena and that the overall rank-frequency distribution of the valency-changing verbs obeys the power law, indicating that the power-law might be prevalent in the valency-changing phenomena. Moreover, the frequencies of bivalent verbs well fit the mixed Poisson distribution, which, with future studies, might help find out some general regularities concerning the use of bivalent verbs.

The current study makes contributions to the field of linguistics by confirming that the English verbs in the valency-changing phenomena also display a pattern that follows Zipf's Law, which has been found in many previous studies as a universal law concerning the minimization of efforts in people's daily communication. Moreover, the present study also extends the scope of research by showing that other important probability distributions, e.g., the mixed Poisson distribution, are also suitable to fit the frequencies of the valency-related constructs. Since there have been few studies exploring the universal patterns of the verbs in the valency-chaning phenomena, the current study might help set the stage for relevant future studies.

However, the data used in the present study only concern the materials from the interviews between an anchorman/anchorwoman and a guest. Thus the findings maybe not be sufficient to uncover the universal patterns of the valency-changing phenomena in the English language. In this regard, future studies can analyze these phenomena by gathering more corpus data and materials from other genres and registers and comparing the results obtained in the present study. In so doing, we can better advance towards the ultimate goal of discovering the universal laws of the valency-changing phenomena.

Funding: This research received no external funding.

Acknowledgments: The authors would like to express their heartfelt thanks to the anonymous reviewers for their invaluable comments and suggestions.

Conflicts of Interest: The authors declare no conflict of interest.

\section{References}

[1] Allerton, D. J. (1982). Valency and the English verb. London/New York: Academic Press.

[2] Altmann-Fitter. (2013). Altmann-Fitter user guide. The 3.1 version.

[3] Cheng, T. (2005, August 27-29). Valency Grammar \& Lexicon-Grammar [Paper presentation]. The 8th National Joint Academic Conference on Computational Linguistics, Beijing, China.

[4] Engel, U. (1982). Syntax der deutschen Gegenwartssprache. Berlin: Schnúdt. 
[5] Fischer, K. (1997). German-English verb valency: A contrastive analysis. Tübingen: Gunter Narr Verlag.

[6] Fischer, K. (2007). Temporary ambiguity of German and English term complements. In T. Herbst, \& K. Götz-Votteler (Eds.), Valency: Theoretical, descriptive and cognitive issues 187-229. Berlin: Walter de Gruyter.

[7] Haugen, T. A. (2013). Adjectival valency as valency constructions: Evidence from Norwegian. Constructions and Frames, 5(1), 35-68. https://doi.org/10.1075/cf.5.1.02hau

[8] Helbig, G., \& Schenkel, W. (1978). Wörterbuch zur Valenz und Distribution deutscher Verben. Leipzig: Bibliographisches Institut.

[9] Herbst, T. (1988). A valency model for nouns in English. Journal of Linguistics, 24(2), 265-301. https://doi.org/10.1017/ S0022226700011804

[10] Herbst, T., \& Götz-Votteler, K. (2007). Valency: Theoretical, descriptive, and cognitive issues. Berlin: Walter de Gruyter.

[11] Herbst, T., Heath, D., \& Roe, I. F. (2004). A valency dictionary of English: A corpus-based analysis of the complementation patterns of English verbs, nouns, and adjectives. Berlin/New York: Mouton de Gruyter.

[12] Heringer, H. J. (1993a). Dependency syntax - Basic ideas and the classical model. In J. Jacobs, A. Von Stechow, \& W. Stemefeld (Eds.), Syntax, Volume 1 298-316 Berlin/New York: Walter de Gruyter.

[13] Heringer, H. J. (1993b). Dependency syntax - Formalized model. In J. Jacobs, A. Von Stechow, \& W. Stemefeld (Eds.), Syntax, Volume $1316-$ 328. Berlin/New York: Walter de Gruyter.

[14] Hua, Z. (2004). German valency in a nutshell. Beijing: Higher Education Press.

[15] Ickler, I. (2007). Sentence patterns and perspective in English and German. In T. Herbst, \& K. Götz-Votteler (Eds.), Valency: Theoretical, descriptive and cognitive issues 187-253. Berlin: Walter de Gruyter.

[16] Jin, H., \& Liu, H. (2018). Regular dynamic patterns of verbal valency ellipsis in modern spoken Chinese. In J. Jiang, \& H. Liu (Eds.), Quantitative analysis of dependency structures 101-118. Berlin: Walter de Gruyter.

[17] Köhler, R., \& Altmann, G. (2009). Problems in quantitative linguistics 2. Lüdenscheid: Ram-Verlag.

[18] Köhler, R. (2012). Quantitative syntax analysis. Berlin: Walter de Gruyter.

[19] Liu, G., \& Du, Y. (2017). A corpus-driven study of verb valency pattern based on APPOINT. Journal of Tianjin Foreign Studies University, 24(6), $1-7$.

[20] Liu, H. (2006). Syntactic parsing based on dependency relations. Grkg/Humankybernetik, 47(3), 124-135.

[21] Liu, H. (2009). Dependency grammar: from theory to practice. Beijing: Science Press.

[22] Liu, H. (2017). An introduction to quantitative linguistics. Beijing: The Commercial Press.

[23] Matthews, P. (2007). The scope of valency in grammar. In T. Herbst, \& K. Götz-Votteler (Eds.), Valency: Theoretical, descriptive and cognitive issues 3-14. Berlin: Walter de Gruyter.

[24] Quirk, R., Greenbaum, S., \& Leech, G. (1985). A comprehensive grammar of the English language. New York: Longman.

[25] Reichardt, R. (2013). Valency sentence patterns and meaning interpretation [Doctoral Dissertation, University of Birmingham]. University of Birmingham Research Archive, E-theses Repository. https://etheses.bham.ac.uk/id/eprint/4645/1/ Reichardt13PhD.pdf

[26] Roe, I. (2007). Valency and the errors of learners of English and German. In T. Herbst, \& K. Götz-Votteler (Eds.), Valency: Theoretical, descriptive and cognitive issues 187-217. Berlin: Walter de Gruyter.

[27] Tesnière, L. (1959). Eléments de syntaxe structurale. Paris: Klincksieck.

[28] Teubert, W. (2007). Sinclair, pattern grammar and the question of hatred. International journal of corpus linguistics, 12(2), 223-248. https://doi.org/10.1075/ijcl.12.2.08teu

[29] Wu, W. (1993). Notes on the verbal valency. Studies of the Chinese Language, 1993(3), 171-180.

[30] Zhen, F., \& Yang, F. (2015). Verb valency in learner English: A corpus-driven study of CONSIDER. Journal of Foreign Languages, 38(6), 57-67.

[31] Zhen, F. (2017). Exploring the integration of valency pattern and meaning: A corpus-driven approach. Foreign Language Research, 2017(04), 13-18.

[32] Zhou, G. (1994). A brief discussion of Chinese valency grammar. Journal of Nanjing Normal University (Social Science Edition), 1994(4), 103106. 